Please do not remove this page

RMIT

UNIVERSITY

\title{
Polybrominated diphenyl ethers and polybrominated biphenyls in Australian sewage sludge
}

Clarke, Bradley; Porter, Nichola; Symons, Robert; Marriott, Philip; Ades, Peter; Stevenson, Gavin; Blackbeard, Judy

https://researchrepository.rmit.edu.au/esploro/outputs/9921863685801341/filesAndLinks?institution=61RMIT_INST\&index=null

Clarke, B., Porter, N., Symons, R., Marriott, P., Ades, P., Stevenson, G., \& Blackbeard, J. (2008).

Polybrominated diphenyl ethers and polybrominated biphenyls in Australian sewage sludge.

Chemosphere, 73(6), 980-989. https://doi.org/10.1016/j.chemosphere.2008.06.034

Published Version: https://doi.org/10.1016/j.chemosphere.2008.06.034

Repository homepage: https://researchrepository.rmit.edu.au

(c) 2008 Elsevier Ltd. All rights reserved.

Downloaded On 2023/04/27 00:03:29 +1000

Please do not remove this page 
Clarke, B, Porter, N, Symons, R, Marriott, P, Ades, P, Stevenson, G and Blackbeard, J 2008, 'Polybrominated diphenyl ethers and polybrominated biphenyls in Australian sewage sludge', Chemosphere, vol. 73, no. 6, pp. 980-989.

1 POLYBROMINATED DIPHENYL ETHERS AND POLYBROMINATED

2 BIPHENYLS IN AUSTRALIAN SEWAGE SLUDGE

3 Bradley Clarke 1,3*, Nichola Porter1,2, Robert Symons3, Philip Marriott1, Peter

4 Ades4, Gavin Stevenson3 and Judy Blackbeard2

5 1School of Applied Sciences, RMIT University, Melbourne, Victoria, Australia.

6 2Co-operative Research Centre for Water Quality and Treatment - Wastewater

7 Program, Melbourne, Victoria, Australia.

8 3National Measurement Institute, Sydney, NSW, Australia.

9 4School of Forest and Ecosystem Science, University of Melbourne, Parkville,

10 Victoria, Australia

11

$12 *$ Corresponding Author

13 RMIT University

14 School of Applied Science (Bld 3 Level 1)

$15 \quad$ Fax +61999253747

$16 \quad$ Phone +61999252117

17 bradley.clarke@student.rmit.edu.au

18 


\section{ABSTRACT}

19 This paper presents a review of the international scientific literature of

20 polybrominated diphenyl ethers (PBDEs) and polybrominated biphenyls (PBBs) in

21 sewage sludge and a survey of sewage sludge from sixteen Australian WWTPs. The

$22 \Sigma$ PBDE mean concentration was $1137 \mu \mathrm{g} \mathrm{kg} \mathrm{g}^{-1}$ d.w. (s.d. 1116 ) and ranged between 5

23 and $4230 \mu \mathrm{g} \mathrm{kg}^{-1}$ d.w. The urban mean of $1308 \mu \mathrm{g} \mathrm{kg}^{-1}$ (s.d. 1320 ) and the rural

24 mean of $911 \mu \mathrm{g} \mathrm{kg}^{-1}$ (s.d. 831) are not statistically different and are similar to

25 international levels. Principal components analysis was performed on the data set and

26 revealed that $76 \%$ of the data variation could be explained by two components that

27 corresponded to overall concentration of the pentaBDE and the decaBDE commercial

28 formulations. An ANOVA was performed comparing PBDEs levels at three WWTPs

29 over the years 2005 and 2006; finding differences between treatment plants (BDE-47)

30 but no significant difference in PBDE levels in the years 2005 and 2006. Low levels

31 of BB-153 were detected in all samples of this survey $(n=16)$; mean $0.6 \mu \mathrm{g} \mathrm{kg}^{-1} \mathrm{~d} . \mathrm{w}$.

32 (s.d. 0.5). This compound has rarely been reported in any other international study.

33 This work highlights the need for a risk assessment of PBDEs in sewage sludge when

34 used for land application, taking into account typical levels found in Australian

35 sludges and soils. 


\section{INTRODUCTION}

37 Due to the widespread use of polybrominated diphenyl ethers (PBDEs) as fire

38 retardants in a wide range of products and as a result of their chemical properties,

39 these chemicals have now accumulated within many environmental compartments.

40 This includes the accumulation of PBDEs within living organisms, resulting in an the

41 exponential increase in concentration in humans over the past twenty-five years

42 (Noren and Meironyte, 2000). The scientific evidence overwhelmingly supports the

43 argument that PBDEs are in fact candidates for inclusion in United Nations

44 Environment Programme's (UNEP) Stockholm Convention on Persistent Organic

45 Pollutants (POPs) i.e., they are environmentally persistent (Law et al., 2006), capable

46 of long-range atmospheric transport (Schmid et al., 2007), bioaccumulate (Harden et

47 al., 2005) and are biologically active (McDonald, 2002). Therefore it is crucial to

48 understand the levels and environmental fate of PBDEs. Sewage sludge is an

49 important medium requiring monitoring for chemical pollution, as one of the

50 responsibilities of wastewater treatment is to prevent the (re)release of chemical

51 pollutants into the environment, and sewage sludge is an important sink of POPs. The

52 analysis of sewage sludge for POPs will provide valuable information about chemical

53 pollution and the risk associated with the re-utilization of sewage sludge as biosolids

54 for land application.

55 PBDEs are a class of brominated fire retardants (BFRs) that have been sold in three commercial formulations under the name of the prominent homologue i.e., pentaBDE, octaBDE, and decaBDE. These commercial formulations contain many BDE congeners (BSEF, 2005). In many nations, the use of PBDE fire retardants is being

59 phased out - in particular, the pentaBDE and octaBDE formulations. Their use has

60 been restricted in many parts of Europe, Japan, some states of U.S.A. as well as in 
61 Australia (BSEF, 2005; NICNAS, 2007). The manufacture and use of polybrominated biphenyls (PBBs) was largely curbed in the 1970s as a result of a serious human contamination incident in Michigan, U.S.A. (IPCS, 1994a). The production of PBBs has been phased out internationally with the last PBBs manufactured in France in 2000 (de Wit, 2002). However, in general, the global demand for BFRs continues to grow substantially with the increasing usage of organic polymer materials in construction, electronic and computer equipment. The global market for BFRs grew from 145,000 tonnes in 1990 (Pettigrew, 1994), to over 310,000 tonnes in 2000 (BSEF, 2005).

The toxicity of PBDEs is slowly becoming understood. PBDEs first gained prominence in the late 1990s when Norén et al. reported an exponential increase in PBDE levels in Swedish mothers' milk over a 25-year period (Noren and Meironyte, 1998). In general, the summed PBDE concentrations in people have increased by a factor of $\sim 100$ during the last 30 years - reaching as high as $190 \mathrm{ng} / \mathrm{g}$ lipid for breast milk from women in the USA in 2000 (Hites, 2004). There is concern among scientists and regulatory authorities due to the high levels of PBDEs in humans (Harden et al., 2005; Schecter et al., 2006; Harrad and Porter, 2007; Schuhmacher et al., 2007; She et al., 2007). In Australia the Department of Environment and Heritage commissioned a study measuring PBDE levels in human milk samples collected in 2002/2003. The mean concentration of PBDEs was $11 \mathrm{ng} / \mathrm{g}$ expressed on a lipid basis and ranged between $6.0 \mathrm{ng} / \mathrm{g}$ and18 ng/g. On a worldwide basis, the levels of PBDE compounds detected in breast milk are higher than those levels observed in Europe and Japan but lower than those observed in North America and Canada (Harden et al., 2005). 
85 Assessment of health risks associated with PBDE human accumulation and exposure

86 is complicated and to date has not been adequately characterized. However the potential risks associated with exposure to the most bio-active congeners (tri- to octaBDE) include thyroid hormone disruption, neuro-developmental defects and cancer (Darnerud et al., 2001; McDonald, 2002). Several studies have shown that PBDEs share the general property of organo-halogenated compounds in which in vivo exposure of rodents results in reduction of serum total and free thyroid hormone (thyroxine (T4)) levels. The implications of altered thyroid hormone function, particularly during development, are profound and have been hypothesized to lead to disrupted brain development and permanent neurological damage (Legler and Brouwer, 2003).

Currently there are no guidelines, either within Australia (NRMMC, 2004) or internationally (U.S. EPA, 1999; European Commission, 2001) that regulate or propose permissible levels of PBDEs or PBBs in sewage sludge for land application. This article summarizes the scientific literature on PBDEs and PBBs levels in sewage sludge and presents results of an Australian sewage sludge survey conducted in 2006. All data reported are on dry weight (d.w.) basis unless otherwise stated.

\section{CHEMICAL PROPERTIES}

There are theoretically 209 PBDE and PBB congeners and they are numbered according to the IUPAC system used for numbering PCBs based on the position of the halogen atoms on the rings. The most common congeners are listed in Table 1.

\subsection{Polybrominated Diphenyl Ethers}

PBDEs have low vapour pressures and are very lipophilic, with $\log \mathrm{K}_{\mathrm{OW}} \mathrm{S}$ in the range 5.9-6.2 for tetra-BDEs, 6.5-7.0 for penta-BDEs, 8.4-8.9 for octa-BDEs and 10 for 
109 deca-BDE (IPCS, 1994b). High $\mathrm{K}_{\mathrm{OW}} \mathrm{S}\left(\log \mathrm{K}_{\mathrm{OW}}>4\right)$ indicate that these compounds

110 will partition strongly into organic material of sewage sludge and that they may

111 bioaccumulate.

112 The pentaBDE ${ }^{1}$ formulation [Cas No: $32534-81-9$ ] is a viscous liquid that contains

$113 \sim 70 \%$ bromine by mass and is mainly used as an additive in polyurethane foam such

114 as furniture foams, and in the manufacture of some textiles. However, the pentaBDE

115 formulation was voluntarily withdrawn from the Japanese market and has been

116 banned in Europe since 2003, in some States of the U.S.A., and recently Australia in

1172007 (Alaee et al., 2003; NICNAS, 2007). Most of the pentaBDE formulation still in

118 use (>97\%) is used in North America (de Wit, 2002). The pentaBDE formulation

119 consists of $41-42 \%$ tetra-BDEs (mainly BDE-47), 44-45\% penta-BDEs

120 (predominately BDE-99 and to a lesser extent BDE-100 (86:14)), and 6-7\% hexa-

121 BDEs (BDE-153 and -154). The three congeners (BDE-47, -99, -100) are also the

122 predominant congeners found in biological matrices including human tissue (de Wit,

123 2002). In addition to the six main congeners listed, minor components have been

124 identified in the pentaBDE formulation, BDE-17, -28, -66, -85, -138, and -183 (Sjodin

125 et al., 1998).

126 The octaBDE formulation [32536-52-0] is a white powder that contains $79 \%$ bromine

127 by mass and is mainly used in the manufacture of acrylonitrile butadiene styrene

128 (ABS) resins, a common thermoplastic used to make light, rigid, moulded products

129 such as musical instruments (recorders) and children's building blocks. The EU

${ }^{1}$ A distinction is made between the PBDE homologues and the commercial formulation by the inclusion of a dash i.e. penta-BDE and pentaBDE respectively. 
announced a ban on marketing of octaBDE in 2002 and Australia banned the use and

131 importation of octaBDE in 2007 (NICNAS, 2007).

132 The decaBDE formulation [1163-19-5] is a white powder containing $83 \%$ bromine

133 content by weight. The decaBDE formulation contains mainly deca-BDE ( $\sim 97-98 \%)$

134 but also contains a small amount of nona-BDE $(\sim 0.3-3 \%)$ (Alaee et al., 2003). The

135 decaBDE formulation is a general purpose flame retardant and can be used in

136 virtually any type of polymer including: polycarbonate, polyester resins, polyolefins,

137 ABS, polyamides, polyvinyl chloride and rubber. The decaBDE mix combined with

138 antimony oxide is used in processes that require high-temperatures such as in the

139 manufacture of high-impact polystyrene used in television and computer monitor

140 cabinets. Despite some debate as to the risks of the decaBDE formulation within the

141 European Parliament, there are currently no regulations regarding the the use of the

142 decaBDE formulation (BSEF, 2005). As of 2007, there are no regulations regarding

143 the use or importation of this product in Australia (NICNAS, 2007).

\section{2.2. Polybrominated Biphenyls (PBBs)}

145 Commercial PBB products are mixtures that are named after the dominant homologue

146 present; however, as with the PBDEs, they contain many other isomers. For example,

147 the commercial formulation commonly sold as "hexabromobiphenyl" (hexaBB) can

148 have hexa-BB concentrations ranging between 60 and 90\% (IPCS, 1994a). There

149 have been 18 different compounds identified in one of these formulations, Fire-Master

150 BP-6 (IPCS, 1994a), with the major hexa-BB identified being $2,2^{\prime}, 4,4^{\prime}, 5,5^{\prime}$ - or BB-

151153 (Sundstrom et al., 1976). The decaBB formulation is reported to have a purity of

152 more than $98 \%$ with the remaining $2 \%$ being nona-BB (IPCS, 1994a). 
153 In the USA and Canada, hexaBB (FireMaster ${ }^{\mathrm{TM}}$ ) was the principal PBB product. It

154 was used as a fire retardant in three main commercial products: ABS plastics, coatings

155 and lacquers, and polyurethane foam (IPCS, 1994a). The use of the hexaBB

156 formulation as a flame retardant in thermoplastic resins was confined to products that

157 do not come into contact with food or animal feed and are not used in fabrics to which

158 humans are exposed (IPCS, 1994a). The use of hexaBB formulations was phased out

159 following the Michigan contamination disaster in the early 1970s (IPCS, 1994a).

160 HexaBB BFRs are banned in North America and in Europe (IPCS, 1994a; de Wit,

$1612002)$.

162 The decaBB formulation (Adine $0102^{\mathrm{TM}}$ ) was used as a flame retardant for

163 thermoplastics and thermosets (e.g., in polyesters, epoxy resins, polystyrene, ABS,

164 polyolefines, and PVC), for elastomers (e.g., in PU-elastomers and India rubber) and

165 for cellulosics (e.g., chip-board). It is frequently used in association with antimony

166 trioxide $\left(\mathrm{Sb}_{2} \mathrm{O}_{3}\right)$ in a similar way to the decaBDE formulation. Its use in paints and

167 varnishes has also been reported (IPCS, 1994a).

168 OctaBB and decaBB formulations were produced in the USA until 1979 (IPCS,

169 1994a). A mixture of highly brominated PBBs called Bromkal 80-9D was produced in

170 Germany until mid 1980s (IPCS, 1994a). Technical grade decaBB (Adine 0102) was

171 produced in France until the year 2000. Currently there are no known producers of

172 PBBs internationally. It is unclear as to the use of PBBs in Australia, however there

173 is no restrictions on the its manufacture, importation or use in Australia (NICNAS,

174 2001). 


\section{SEWAGE SLUDGE}

176 There is a relatively small set of scientific literature that examines the issue of PBDEs

177 and PBBs in sewage sludge. The use of PBBs has not resulted in the widespread

178 distribution of PBBs in the environment or in sewage sludge, particularly when

179 compared to the ubiquitous PBDEs (de Wit, 2002). The concentration of PBDEs in

180 environmental matrices has increased dramatically since measurements were begun

181 and are now found to be accumulating in most environmental compartments,

182 including sewage sludge (de Wit, 2002). There have been comprehensive studies in

183 Australia investigating PBDEs in environmental matrices, however, there have been

184 no studies focusing specifically on sewage sludge. This review of the international

185 body of work examining PBDEs in sewage sludge should aid in our understanding of

186 the typical levels of PBDEs in sludge, as well as the source and environmental fate of

187 these compounds. PBDEs and PBBs are assumed to circulate within the environment

188 in much the same way as other persistent halogenated compounds.

\section{HISTORICAL LEVELS OF PBBS AND PBDES IN SEWAGE SLUDGE}

\subsection{Polybrominated Diphenyl Ethers}

191 PBDEs were first detected in sewage sludge and other environmental samples in 1979

192 from samples collected near chemical manufacturing sites in the U.S.A. (de Carlo,

193 1979). However, it wasn't until 1992 that Nylund et al. first reported the

194 concentration of two common PBDEs congeners found in sludge $\left(2,2^{\prime}, 4,4^{\prime}\right.$ - tetra-

195 BDE (BDE-47) and 2,2',4,4',5-penta-BDE (BDE-99) of $15 \mu \mathrm{g} \mathrm{kg}^{-1}$ and $19 \mu \mathrm{g} \mathrm{kg}^{-1}$

196 respectively), which are both components of the pentaBDE formulation (Nylund et

197 al., 1992). These levels were similar those reported in a 1992 study by Hagenmaier et

198 al. with $\sum$ penta-BDE ranging from 0.22 and $17.13 \mu \mathrm{g} \mathrm{kg}^{-1}$ with an average of $8.58 \mu \mathrm{g}$ 
$199 \mathrm{~kg}^{-1}, \mathrm{n}=13$ (Hagenmaier et al., 1992). Hagenmaier et al. also reported the consistent 200 presence of brominated furans (PBDF) at relatively high concentrations (ranging from $2010.21-3.05 \mu \mathrm{g} \mathrm{kg}^{-1}$ and a mean of $\left.1.17 \mu \mathrm{g} \mathrm{kg}^{-1}\right)$, which are similar to the

202 concentration of the chlorinated dioxins and furans (Rappe et al., 1998). Hagenmaier 203 stated "there is a reasonably good correlation between the concentrations of PBDFs 204 and PBDEs" and suggested that the PBDEs are the source of PBDFs observed in 205 sludge. This is extremely important and requires more research, as PBDFs share the 206 same level of toxicity as the chlorinated furans (IPCS, 1989, 1998).

207 The results reported by Nylund et al. (1992) and Hagenmaier et al. (1992) are 208 surprisingly low when compared to other modern literature. For example the sludge 209 samples collected in 1997-1998 from Stockholm, Sweden, reflect concentrations of 210 PBDEs in sludge more typical of those in contemporary sludges i.e. BDE-47 levels of 21178,80 and $36 \mu \mathrm{g} \mathrm{kg}^{-1}$; BDE-209 levels of 220, 270 and $170 \mu \mathrm{g} \mathrm{kg}{ }^{-1}$. The 212 concentrations of BDE-47, $-99,-100$, and -209 were first presented by de Wit based 213 upon work of Sellstrom et al. and are presented in Table 3 (Sellstrom et al., 1999; de 214 Wit, 2002). These results show a higher burden of BDE-209 compared to the other 215 congeners from the pentaBDE formulation.

216 The dominance of BDE-209 was demonstrated again with findings by de Boer et al. 217 when concentrations of up to $920 \mu \mathrm{g} \mathrm{kg}^{-1}$ found in sludge samples from The 218 Netherlands (de Boer et al., 2000a). de Boer et al. also reported the concentration of 219 BDE-47, -99, -153 and -209 on suspended particulates in WWTP influent and 220 effluent, finding that BDE-47 and BDE-209 increased in concentration from an 221 average of 2.3 to $22 \mu \mathrm{g} \mathrm{kg}^{-1}$ and 24 to $350 \mu \mathrm{g} \mathrm{kg}^{-1}$ respectively in WWTP influents 222 and effluents (de Boer et al., 2000b). Unfortunately, the amount of suspended 223 material that was typical of these water samples was not provided, and should be 
224 considerably lower in effluent than influent. It is not surprising that PBDEs are found 225 on suspended solids, since highly hydrophobic organic compounds will partition to 226 the sludge and suspended solids in preference to water through the WWTP process. 227 However, this finding may have consequences for the use of treated effluent, perhaps 228 requiring a higher level of treatment before effluent can be reused or discharged into 229 the environment. The presence of PBDEs in secondary treated effluent was also 230 reported by North in 2004. The congeners BDE-47, -99 and -209 were detected in 231 wastewater effluent at 10, 11 and $2 \mathrm{ng} \mathrm{L}^{-1}$ respectively (North, 2004). Again the 232 amount of suspended material was not reported. Hamm (2004) presented the PBDE 233 levels of eight German WWTP sewage sludges and suspended particulate matter from 234 their effluent. The total tri- to deca-BDE concentrations ranged from 231 to $982 \mu \mathrm{g}$ $235 \mathrm{~kg}^{-1}$ (mean of $544 \mu \mathrm{g} \mathrm{kg}^{-1}$ ) for sludges and from 71 to $353 \mu \mathrm{g} \mathrm{kg}^{-1}$ (mean of $209 \mu \mathrm{g}$ $236 \mathrm{~kg}^{-1}$ ) for the suspended particulate matter (Hamm, 2004).

237 In 2001, Hale et al. reported the total concentration of penta-BDEs in USA biosolids 238 as 1100 to $2290 \mu \mathrm{g} \mathrm{kg}^{-1}$ suggesting that input was consistently high, regardless of the 239 region and irrespective of preliminary treatment. These levels are far higher than 240 previously reported and exceeded those in European sludges by 10 - to 100- fold. This 241 was attributed to the much higher use of PBDEs, both the pentaBDE and the 242 decaBDE formulations, within the U.S.A. Unlike BDE-99 and -100 (both part of 243 pentaBDE formulation), BDE-209 varied widely among the biosolids analyzed 244 ranging from $84.8-4890 \mu \mathrm{g} \mathrm{kg}^{-1}$. Incidentally, Hale et al. (2001) also reported that a 245 fish caught from a Virginia stream contained $47900 \mathrm{ng} \mathrm{g}^{-1}$ (or $48 \mathrm{ppm}$ ) of total 246 PBDEs, one of the highest environmental burdens ever reported. In further work 247 investigating the levels of PBDEs in the U.S.A. in raw and treated sludges, Hale et al. 248 found an average total PBDEs of $1540 \mu \mathrm{g} \mathrm{kg}^{-1}$ (Hale et al., 2002), while North 
249 (2004a) found BDE-209 concentrations of $1183 \mu \mathrm{g} \mathrm{kg}^{-1}$ and the $\sum$ PBDE

250 concentration up to $3955 \mu \mathrm{g} \mathrm{kg}^{-1}$ (North, 2004).

251 In 2002, Oberg et al. reported the concentration of PBDEs and PBB-153 in 116

252 sewage sludge samples. Unfortunately the results were reported on a wet weight basis 253 making it impossible to compare the levels determined with other international 254 literature, as the water content of sewage sludge is highly variable. Oberg et al. does, 255 however, report the detection of PBB-153 (Oberg et al., 2002).

256 Fabrellas et al. (2004) found that the major PBDE constituent of sludge $(<95 \%)$ is 257 BDE-209 with concentrations ranging between 786 and $5837 \mu \mathrm{g} \mathrm{kg}^{-1}$. In an 258 industrial sewage sludge sample the concentration of BDE-209 was the highest ever 259 reported at $18032 \mu \mathrm{g} \mathrm{kg}^{-1}$. Despite the relatively low concentrations of the total tri260 to hexa-BDE levels (5.3 and $177.3 \mu \mathrm{g} \mathrm{kg}^{-1}$ respectively) relative to deca-BDE, these 261 concentrations are still relatively high compared to other studies. The congener ratios 262 resemble the pattern of the commercial pentaBDE formulation (Fabrellas et al., 2004).

263 In 2006, Law et al. reported the results of Swedish sludge analyzed for BDE-47, -99, $264100,-153,-154,-209$. Law et al. found that BDE-209 was the dominant species, with 265 highly variable concentrations ranging from 5.6 to $1000 \mu \mathrm{g} \mathrm{kg}^{-1}$ and an average 266 concentration of $120 \mu \mathrm{g} \mathrm{kg}^{-1}$ (Law et al., 2006). Again the congener profile of BDE$26747,-99,-100,-153$ and -154 in all the Swedish sludges was similar to that of the 268 pentaBDE technical product, which is probably the original source. Concentrations of 269 the lower brominated PBDEs were fairly similar in all sewage sludge samples, 270 indicating diffuse leaching of these from products into wastewater streams (Law et al., 271 2006). 
272 Knoth et al. (2007) reported the concentration of PBDEs in 39 sludge samples from

273 different stages of the WWTP process from 11 municipal wastewater treatment plants

274 in Germany, which were collected from March 2002 to June 2003. The total tri- to

275 hepta-BDE concentrations (sum of BDE -28, -47, -99, -153, -154 and -183) ranged

276 from 12.5 to 288 (mean $108 \mu \mathrm{g} \mathrm{kg}^{-1}$ ). The BDE-209 concentrations once again varied

277 widely between 97 to $2217 \mu \mathrm{g} \mathrm{kg}^{-1}$ (mean $256 \mu \mathrm{g} \mathrm{kg}^{-1}$ ) and was again the most

278 prevalent congener detected (Knoth et al., 2007). No change in the tri- to hepta-BDE

279 congener profile ratios was observed (\% of total BDE $-28,-47,-99,-153,-154,-183$

280 without -209) in sludge from different stages of the waste water treatment process

281 (primary sludge, secondary excess sludge and dewatered digested sludge), which

282 suggested that the degradation of BDE-209 and other higher brominated PBDEs to

283 other lower brominated congeners did not occur.

284 Sludge samples collected from 31 WWTPs in 26 cities in China were analyzed for

285 PBDEs and organochlorine pesticides (OCPs) (Wang et al., 2007). The concentrations

286 of $\sum$ PBDE (sum of congeners $-17,-28,-47,-66,-71,-85,-99,-100,-138,-153,-154$,

287 and -183) ranged from 6.2 to $57 \mu \mathrm{g} \mathrm{kg}^{-1}$. The concentration of BDE-209 ranged from

288 below limit of detection $\left(<1 \mu \mathrm{g} \mathrm{kg}^{-1}\right.$ ) to $1109 \mu \mathrm{g} \mathrm{kg}^{-1}$ (with a median of $27 \mu \mathrm{g} \mathrm{kg}^{-1}$ ),

289 and mean of 55\% (median 69\%) of the total PBDEs. These levels are about $10-100$

290 times lower than those found in Europe and North America. PBDE levels in sludge

291 were not found to depend on the location or treatment capacity of the WWTPs.

292 To summarize, the major congeners present in sewage sludge are BDE-47, -99 and -

293209 and the $\Sigma$ PBDE concentrations are typically present in the $\mu \mathrm{g} \mathrm{kg}^{-1}$ to the low $\mathrm{mg}$

$294 \mathrm{~kg}^{-1}$ range. These congeners represent the major commercial formulations of

295 pentaBDE (BDE-47, -99) and decaBDE (BDE-209), which appear to be the original

296 source. 


\subsection{Polybrominated Biphenyls (PBBs)}

298 The concentration of PBBs in sewage sludge has received little attention, primarily

299 because of the relatively low use of PBBs in manufacturing. In general, the few

300 studies $(n=3)$ that have investigated the levels of PBBs in sludge showed PBBs to be

301 below the detection limit (de Carlo, 1979, de Boer et al., 2003, de Boer et al., 2000).

302 In 2000, the presence of PBB was not detected in WWTP influent or effluent or other

303 environmental samples analysed (de Boer et al., 2000b). In 2003, de Boer again

304 analysed environmental samples for PBBs. This time they analysed the samples of

305 influents, effluents and suspended particulate matter from a Swedish wastewater

306 treatment plant for PBBs $-15,-49,-52,-101,-153,-169$ and -209 but they were, once

307 again, below the detection limit. (de Boer et al., 2003). The detection limits for most

308 PBBs were between $<0.1$ and $<1 \mu \mathrm{g} \mathrm{kg}^{-1}$, but for PBB-209 the detection limits were

309 generally between $<1$ and $<10 \mu \mathrm{g} \mathrm{kg}^{-1}$. This result is in agreement with the

310 negligible PBB production in Europe over the past decades (de Boer et al., 2003). It

311 is unclear as to whether these compounds have degraded or have been diluted to

312 undetectable levels or are seldom used within society. Analytically, it has only been

313 since the development of isotopically labelled standards, and the advent of facilities

314 with ultra-trace capability, using high-resolution mass spectrometry in the late $2007 \mathrm{~s}$,

315 that the detection of PBBs has been made possible with a certain degree of certainty.

316 5. SOURCES OF PBDES IN SEWAGE SLUDGE

317 Release of PBDEs into wastewater may occur during their synthesis, during

318 incorporation into polymers or related finished products, during their use and disposal

319 or recycling of these products, by cycling in the environment, or a combination of the

320 above. As PBDEs are hydrophobic, resistant to degradation and widely used in

321 products, it is logical to assume that some enter the wastewater treatment plant 
322 process and will subsequently be concentrated in high organic carbon-containing

323 sewage sludges. However, evidence published by de Boer et al. (2003) and North

324 (2004) have indicated that the common BDEs (-49, -99 and -209) are also present in

325 the WWTP effluent, or more specifically, the suspended organic material. In a study

326 conducted by (Hale, 2001) examining 11 sludges collected from four different regions

327 of the U.S.A., the constituents of pentaBDE formulation were detected in all 11

328 sludges analysed. The sludge had been stabilized in preparation for eventual land

329 application. Concentrations (total of BDE-47, -99, -100, -153 and -154) were fairly

330 consistent with concentrations ranging from 1100 to $2290 \mu \mathrm{g} \mathrm{kg}^{-1}$ despite differences

331 in facility location, industrial base and sludge stabilization process. This suggests that

332 the source is domestic in origin as it is consistently present regardless of region. In

333 contrast, levels of BDE-209 varied substantially between samples, ranging between

33484.8 to $4890 \mu \mathrm{g} \mathrm{kg}^{-1}$, which suggests that the source of this compound is more

335 random and derives from an industrial source or other variable source. Another

336 alternative is that BDE-209's higher bio-degradability relative to other PBDEs

337 (Bezares-Cruz et al., 2004), may cause the high variability in concentration observed.

\section{$338 \quad$ 6. METHODS}

339 The results of two studies are reported. The first is a report on the concentration of

340 PBDEs in sewage sludge samples taken from sixteen WWTPs from around Australia

341 in 2006. The second is an analysis of PBDE levels in sewage sludge samples from

342 three WWTPs over two successive years. The analyses were conducted at the

343 National Measurement Institute (NMI), Sydney (Pymble), Australia. Sludge samples

344 were extracted using accelerated solvent extraction (ASE) and the extracts were

345 subsequently treated with concentrated sulfuric acid, treated for inorganic and organic

346 sulfur by copper and silver nitrate clean-up techniques respectively, and then 
chromatographically purified using a commercial automated clean-up procedure

348 (PowerPrep ${ }^{\mathrm{TM}}$ ). Analyses were undertaken for chlorinated PBDEs and PBBs using

349 isotope dilution capillary gas chromatography-electron impact high-resolution mass

350 spectrometry with monitoring of either $\mathrm{M}^{+},[\mathrm{M}+2]^{+}$or $[\mathrm{M}+4]^{+}$ions. The analytical

351 procedure was based upon standard U.S. EPA methodologies (U.S. EPA, 1994).

\subsection{Instrumental Technique}

353 Instrument: GC HP 6890 coupled to Finnigan MAT 95XL HRMS. Column: DB-5 354 column $10 \mathrm{~m} \times 0.1 \mathrm{~mm} \times 0.1 \mu \mathrm{m}$. Inj. Temp: $280{ }^{\circ} \mathrm{C}$ Transfer line (DB-5): $280{ }^{\circ} \mathrm{C}$

355 Temperature program: Initial temperature $120^{\circ} \mathrm{C}$ hold $2 \mathrm{~min}, 120-230{ }^{\circ} \mathrm{C}$ at 15

$356{ }^{\circ} \mathrm{C} / \min , 230-320{ }^{\circ} \mathrm{C}$ at $5{ }^{\circ} \mathrm{C} / \min 320^{\circ} \mathrm{C}$ then hold 5 min Carrier Gas: Helium, 357 constant flow mode $(0.4 \mathrm{~mL} / \mathrm{min})$ Injection volume: $1 \mu 1$ splitless MS Parameters 358 Ionisation Mode: Electron Impact; Ion Source: $280{ }^{\circ} \mathrm{C}$; Electron energy $70 \mathrm{eV}$; 359 Filament Current: $0.7 \mathrm{mV}$; Electron Multiplier Voltage: Set to produce a gain of $10^{6}$.

\section{$360 \quad$ 6.2. Australian Sewage Sludge Survey 2006}

361 A national survey of sewage sludge $(n=16)$ was conducted, collecting samples from

362 each state and the Northern Territory of Australia during 2006 by requesting samples

363 from participating WWTPs. Sampling kits were provided to on-site workers who

364 collected fresh sewage sludge samples, preferably at the last stage before land

365 application and not taken from the top of the sludge pile. Samples were collected in

366 pre-cleaned $250 \mathrm{~mL}$ amber glass jars with teflon lined lids and sent via courier to

367 NMI for analysis. A variety of samples from urban (population $>1000000$ ) and

368 rural (population $<300$ 000) WWTPs were collected. Table 4 describes the treatment 369 process for each of the participating WWTPs. 


\subsection{Comparison of PBDE Levels Over Time}

371 The concentration of PBDEs was measured in sludge samples from three WWTP,

372 collected in duplicate, during the years 2005 and 2006. Table 5 lists the WWTPs

373 from which sewage sludge samples were collected. Sample collection and analysis

374 methods were the same as for the Australian Sewage Sludge Survey.

381 for this analysis.

382 In the study of variation in PBDEs over time, analysis of variance was used to test

383 whether there were effects of year, WWTP or a year by WWTP interaction. WWTP

384 effects were considered to be fixed while year and the interaction were considered as

385 having random effects.

\subsection{Statistical Analysis}

Principal components analysis was performed to analyse the relationship among the PBDE congeners using the software package NTSYSpc version 2.20 (Exeter

Software). The raw concentration data for each compound were standardised to mean of zero and standard deviation of oneand the PCA conducted on the correlation matrix of the standardized data. Values below the detection limit were assumed to be zero

\section{RESULTS AND DISCUSSION}

\subsection{Analytical Discussion - Identification of BB-153}

It is well known that there is co-elution on a DB-5 column between BB-153 and BDE-154. Therefore using any of the following techniques viz. GC-ECD, GC-NICIMS and GC-EI-LRMS, can lead to an overestimation of either compound. The GCEI-HRMS method used in this study overcomes these limitations by careful selection of the respective quantification and confirmatory ions for labelled surrogates and 
native compounds, as well as operating the mass spectrometer at high resolution $(\mathrm{R}>10,000)$, thereby ensuring accurate identification and quantification. The ions

selected for the ${ }^{13} \mathrm{C}_{12}$ BB-153 surrogate and the native BDE-154 represent $(\mathrm{M}+-2 \mathrm{Br}){ }^{+2}$ and $(\mathrm{M}+-2 \mathrm{Br})^{+6}$, respectively. These ions are less abundant $(<65 \%)$ compared to the $\mathrm{M}-2 \mathrm{Br}$ ions but can be mass resolved from one another with an instrument resolution of $>10,000$. This approach has been validated by analysing certified standards, procedural blanks and samples containing high BB-153 and BDE-154 levels and follows the recommended ions in the Certificate of Analysis supplied by Wellington Laboratories. The results presented here should therefore not be appreciably upwardly biased.

\subsection{Australian Sewage Sludge Survey 2006}

\subsubsection{Polybrominated Diphenyl Ethers}

The concentration of PBDEs as measured in the sixteen sewage sludge samples is supplied in Table 6. An estimate of the error associated with each analytical measurement has been calculated by the relative error of duplicate samples measured as part of the time study. A visual representation of BDE-47, $-99,-209$, as well as $\Sigma$ PBDEs concentrations found in this survey are presented in Fig. 2 and a comparison with the results of this study and the international literature are presented in Fig. 3

\section{Examination of the correlation matrix revealed that there were three primary groups} of compounds; with correlations high among congeners within groups and low with congeners of other groups. The first two groups contained congeners that were are representative of the pentaBDE and decaBDE formulations. The basis for group separation is that the individual congeners in each group are highly correlated with one another, they are the reported constituents of the commercial formulation and 
417 they are present in similar ratios to those reported in the formulations. The ratio of 418 the principal congeners of the pentaBDE formulation BDE 47:99+100:153+154 have 419 a ratio of 41:51:8 which is similar to the reported ratio of 40:45:6 (Sjodin et al., 1998). 420 The principal congeners of the decaBDE formulation BDE 209:206+207+208, 421 reported to have a ratio of 97-98:0.3-3 were found in an overall ratio of 93:7 (Alaee et 422 al., 2003).

423 The first two principal components explained $76 \%$ of the variation within the sample set. PCA1 was primarily representative of the average concentration of components 425 in the pentaBDE formulation (BDE-47, $-49,-66,-77,-85,-99,-100,-119,-139,-140$, $426-153,-154)$ explaining $50 \%$ of sample variation and PCA2 corresponded to 427 representative congeners of the decaBDE formulation (BDE-201, -203, -206, -207, 428208 and -209), explaining an additional $26 \%$ of the sample variation. The third 429 component explained $13 \%$ of the data variation, however it was concluded that this 430 component was not meaningful, as it corresponded mainly with variation in congeners 431 that were at or below their detection limits (BDE-171, -180, -184 and -191). Given 432 the high correlations within formulations, the concentration of PBDEs could be 433 reasonably summarised by the concentration of three dominant congeners, BDE-47 434 and BDE-99 and representing the pentaBDE formulation and BDE-209 representing 435 the decaBDE formulation. A plot of PCA1 vs PCA2 (i.e. pentaBDE vs decaBDE 436 formulations) does not reveal any obvious trends, such as associations with size of 437 town (population) or industrialisation (Fig. 4.)

438 If the PBDEs in sewage sludge were derived mainly from domestic products one 439 would expect there would be consistency in the relative concentrations of PBDEs 440 regardless of region. Using BDE-47 and BDE-99 as representatives of the pentaBDE 441 formulation this proposal is confirmed; the mean of BDE-47 and BDE-99 of $136.5 \mu \mathrm{g}$ 
$442 \mathrm{~kg}^{-1}$ (s.d. $112 \mu \mathrm{g} \mathrm{kg}^{-1}$ ) and $138 \mu \mathrm{g} \mathrm{kg}{ }^{-1}$ (s.d. 116) respectively. Therefore it is

443 suggested that the primary source of the pentaBDE formulation in Australian sewage 444 sludge is largely from domestic sources. Concentration of the decaBDE formulation, 445 on the other hand is highly variable (mean BDE-209 $715 \mu \mathrm{g} \mathrm{kg}^{-1}$, s.d. 981), consistent 446 with previous reports in the scientific literature (Hale, 2001), suggesting a less 447 uniform source than the domestic environment. Varied industrial applications could 448 explain the variation observed. An alternative hypothesis is that the high variability 449 of BDE-209 is due to the higher degradation rate of this compound relative to the 450 lower substituted PBDEs (Bezares-Cruz et al., 2004).

451 Among the samples two are quite unusual. These are urban WWTP U5 and rural 452 WWTP R7. The urban WWTP U5 has an atypically high BDE-209 concentration. 453 Sewage sludge may be stabilized for biosolids using a variety of methods and this 454 elevated concentration may be a result of this method i.e. longer preparation time 455 (three years) and the subsequent loss of organic material compared to other sludges.

456 Similarly, treatment plants $\mathrm{R} 1$ and $\mathrm{R} 8$, both lagoon processes that degrade organic 457 material over time, have the second and forth highest $\Sigma$ PBDE concentrations in this 458 study. Regardless of whether BDE-209 has been concentrated, its continued elevated 459 concentration in sewage sludge that is has been aged three years contradicts 460 laboratory evidence of the faster degradation of BDE-209 compared to the other lower 461 brominated congeners (Bezares-Cruz et al., 2004; Eriksson et al., 2004). This 462 contradiction over the persistence of BDE-209 was found also in a 2005 Swedish field 463 trial that found elevated levels of PBDEs, including BDE-209 (2 $200 \mu \mathrm{g} \mathrm{kg}^{-1}$ 464 compared to the control of $0.75 \mu \mathrm{g} \mathrm{kg}^{-1}$ ) twenty years after the last use of PBDEs at 465 that site, and found no evidence of the photodebromination of BDE-209 in the soils 466 studied (Sellstrom et al., 2005). Future analysis should also include total organic 
carbon measurements as well as dry weight measurements to allow more accurate

468 comparison of the concentrations reported. The other notable feature of sample U5 is

469 the low burden of the pentaBDE formulation congeners. It is possible that this

470 treatment of sewage sludge (i.e. storage for three years) may have allowed the off-site

471 movement of these compounds by atmospheric transport.

472 The other unusual sample is rural WWTP R7, which has almost no PBDE burden.

473 This is quite an anomaly both within the current sample set and the international

474 literature. If the source of pentaBDE formulation congeners is domestic, one would

475 expect there to be similar concentrations in all sludges regardless of region of

476 wastewater treatment process. WWTP R7 is a small community that services an

477 abattoir and it is possible that this treatment plant processes large volumes of animal

478 waste, which may have lowered the PBDE burden by dilution.

479 To provide a context in which to assess the magnitude of these PBDE burdens they

480 have been compared to the contamination limits for the chemically similar

481 polychlorinated biphenyls (PCBs). In Australia, the National contamination limits

482 are Contamination Limit 1 of $200 \mu \mathrm{g} \mathrm{kg}^{-1}$ (restricted land application) and

483 Contamination Limit 2 of $1000 \mu \mathrm{g} \mathrm{kg}^{-1}$ (unsuitable for land application) (NRMMC,

484 2004), which are similar to those in several European nations (European Commission,

485 2001). If it were appropriate to translate these guidelines directly from the PCB

486 contamination limits to a PBDE contamination limit, then all samples, except WWTP

487 R7, would be unsuitable for unrestricted land application. Fifteen of the sixteen

488 samples had a $\Sigma$ PBDEs greater than $200 \mu \mathrm{g} \mathrm{kg}^{-1}$ and seven of the sixteen samples

489 contained $\Sigma$ PBDEs greater than $1000 \mu \mathrm{g} \mathrm{kg}^{-1}$. At this time no contaminant limits

490 have been proposed for PBDEs and the practice of sewage sludge land application has

491 not stopped in the U.S.A. and many other nations despite higher PBDE burdens than 

those observed in Australia. However, the PBDE levels found in Australian sludges are ten to one hundred times greater than levels of PBDEs in European soils; $\Sigma$ PBDEs $0.065-12 \mu \mathrm{g} \mathrm{kg}^{-1}$ (Hassanin et al., 2004) and suggests that the land application of sludge would increase the PBDE burden found in soils.

To summarise, the mean concentration of $\Sigma$ PBDEs in this Australian survey was 1 $137 \mu \mathrm{g} \mathrm{kg}^{-1}$ (s.d. 1 116). When comparing the urban mean of $1308 \mu \mathrm{g} \mathrm{kg}$ (s.d. 1 320) and the rural average of $911 \mu \mathrm{g} \mathrm{kg}^{-1}$ (s.d. 831) there is little variation and the difference is not significant at the $95 \%$ confidence level. The PBDE concentrations reported in this study are similar to those reported in the international scientific literature (Fig. 3). Principal component analysis revealed that this data set could be reduced into two primary components reflecting the pentaBDE and decaBDE formulations and these two formulations can be suitably represented by the dominant congeners BDE-47, -99 and BDE-209 respectively.

\subsection{Polybrominated Biphenyls}

The finding of BB-153 in all samples is unexpected (mean $0.6 \mu \mathrm{g} \mathrm{kg}^{-1}$, s.d. 0.5) and, as far as is known, there are no industries utilizing the hexaBB formulation in Australia. In terms of historical use, it is unclear whether this compound was ever used in Australia. Despite this lack of knowledge, it is possible that the commercial formulation of hexaBB was utilized in Australia. The ubiquity of BB-153 strongly suggests that it was in a common product, such as automobiles or widely used domestic products. However the use of hexaBB in Australia would be surprising considering it was banned from many Western nations in the 1970s following the Michigan contamination disaster. It is likely that BB-153 could was imported with an unknown product, which was commonly used and widely distributed. A more 
516 concerning hypothesis is that this chemical is extremely persistent in the environment

517 and has been subject to long-range atmospheric transport.

\subsection{Variation of PBDE Levels Over Time}

519 An analysis of variance was performed on the concentration of the three components 520 BDE-47, -99,-209 as well as PPBDEs at three Perth WWTPs (Beenyup, Subiaco and 521 Woodmans Point) over two years $(2005,2006)$. From the correlation matrix (R) and 522 principal component analysis previously performed, PBDE congeners were separated 523 into groups that have been identified as the pentaBDE and decaBDE formulations.

524 Given the high correlations within formulations, it is appropriate to conduct an 525 analysis of variance on just the dominant congeners representative of each viz. BDE526 47\&-99 and BDE-209. Other congeners were measured and the raw data are provided 527 in Table 8.

528 In all three cases there was a significant WWTP by year interaction indicating that 529 differences in concentration existed between the WWTPs but the magnitudes of these 530 differences varied depending on the year of measurement. Despite the interaction 531 there were significant differences between WWTPs, but not between years, for BDE-

532 47. The concentration of BDE-47 was significantly lower at Subiaco $\left(60 \mu \mathrm{g} \mathrm{kg}^{-1}\right)$ 533 than at the other two plants: Beenyup $213 \mu \mathrm{g} \mathrm{kg}^{-1}$, Woodman Point $285 \mu \mathrm{g} \mathrm{kg}^{-1}$. The 534 concentrations of BDE-99, -209 and $\Sigma$ PBDEs were also lower, at Subiaco than at 535 Beenyup and Woodmans Point (Table 8). There were no overall differences between 536 years or WWTPs for either BDE-209 or $\Sigma$ PBDEs. The similar result for BDE-209 and $\Sigma$ PBDEs is not surprising as BDE-209 is by for the most abundant congener. 


\section{CONCLUSION}

539 A survey of Australian sewage sludge in 2006 found the $\Sigma$ PBDE mean concentration

540 to be $1137 \mu \mathrm{g} \mathrm{kg}^{-1}$ d.w. (s.d. 1 116), with little difference between the urban (mean 1

$541308 \mu \mathrm{g} \mathrm{kg}^{-1}$, s.d. 1320 ) and the rural (mean $911 \mu \mathrm{g} \mathrm{kg}{ }^{-1}$, s.d. 831) samples. The

542 PBDE levels in Australian sewage sludge reported in this study are similar to PBDE

543 levels reported in the international scientific literature. Fifteen of the sixteen samples

544 contained $\sum$ PBDE greater than $200 \mu \mathrm{g} \mathrm{kg}^{-1}$ and seven were higher than $1000 \mu \mathrm{g} \mathrm{kg}^{-1}$

545 (Australian guidelines values for $\Sigma$ PCBs in sewage sludge land application). The

546 PBDE burden found in Australian sludge is far higher than the levels reported in

547 European soils. If Australian soils have a similar PBDE burden to European soils,

548 then sludge land application is likely to increase the PBDE levels in soil. The

549 development of guidelines that estimate the risk of PBDEs in sewage sludge land

550 application, taking into account typical PBDE concentration in Australian soils,

551 should be developed.

552 Both the pentaBDE and decaBDE formulations appear to go through the WWTP

553 system unchanged. The concentration of pentaBDEs was found to be fairly

554 consistent in concentration in the sludges surveyed, suggesting domestic sources,

555 whereas the decaBDE formulation was found to be variable, which is best explained

556 by different industrial inputs. Further research is suggested to clarify the sources of

557 these compounds in WWTPs.

558 The finding of BB-153 in all samples analyzed as part of this survey is unexpected.

559 The results further demonstrate that PBBs are extremely environmentally persistent

560 and that they are not only capable of long-range atmospheric transport, but are also

561 now widely distributed within the Australian environment. The concentrations of

562 PBBs in sewage sludge are not high, however, they are rarely analysed, detected or 
reported in the international scientific literature due to a phasing out of these

564 compounds in 1970s.

565 This is the first article to comprehensively focus on PBDEs and BB-153 in Australian

566 sewage sludge and the first to provide a review of the international literature

567 specifically on PBDEs and PBBs in sewage sludge. We have identified the issue of

568 PBDEs in Australian sewage sludge as a potential problem for sewage sludge land

569 application and further research is required to ascertain the risks to human health and

570 the environment from this practice.

\section{ACKNOWLEDGEMENTS}

572 The authors would like to acknowledge the water treatment authorities that kindly

573 supplied samples and permitted it to be released publicly. BC gratefully acknowledges

574 the financial support of Wastewater Program of the Cooperative Research Centre for

575 Water Quality and Treatment, the Water Corporation of Western Australian and the

576 Victorian Department of Human Services.

\section{10. REFERENCES}

578 Alaee, M., Arias, P., Sjodin, A., Bergman, A., 2003. An overview of commercially

579 used brominated flame retardants, their applications, their use patterns in different

580 countries/regions and possible modes of release. Environ. Int. 29, 683-689.

581 Bezares-Cruz, J., Jafvert, C.T., Hua, I., 2004. Solar Photodecomposition of

582 Decabromodiphenyl Ether: Products and Quantum Yield. Environ. Sci. Technol. 38, $583 \quad 4149-4156$.

584 BSEF, 2005. Bromine Science and Environmental Forum. Accessed 31 May 2005

$585 \quad$ www.bsef.com 
586 Darnerud, P.O., Eriksen, G.S., Johannesson, T., Larsen, P.B., Viluksela, M., 2001.

587 Polybrominated Diphenyl Ethers: Occurances, Dietary Exposure, and Toxicology.

588 Environ. Health. Persp. 109 (suppl 1).

589 de Boer, J., de Boer, K., Boon, J.P., 2000a. Polybrominated Biphenyls and

590 Diphenylethers. In: Hutzinger, O. (Ed.). The Handbook of Environmental Chemistry:

591 New Types of Persistent Halogenated Compounds.

592 de Boer, J., Horst, A., Wester, P.G., 2000b. PBDEs and PBBs in Suspended

593 Particulate Matter, Sediments, Sewage Treatment Plant in- and Effluents and Biota

594 From the Netherlands. Organohalogen Compounds 27, 85-88.

595 de Boer, J., Wester, P.G., van der Horst, A., Leonards, P.E.G., 2003. Polybrominated

596 diphenyl ethers in influents, suspended particulate matter, sediments, sewage

597 treatment plant and effluents and biota from the Netherlands. Environ. Poll. 122, 63-

59874.

599 de Carlo, V.J., 1979. Studies of brominanted chemicals in the environment. Ann. NY.

600 Acad. Sci. 320, 678-681.

601 de Wit, C.A., 2002. An overview of brominated flame retardants in the environment.

602 Chemosphere 46, 583-624.

603 Eriksson, J., Green, N., Marsh, G., Bergman, A., 2004. Photochemical Decomposition

604 of 15 Polybrominated Diphenyl Ether Congeners in Methanol/Water. Environ. Sci.

605 Technol. 38, 3119-3125.

606 European Commission, 2001. Organic Contaminants in Sewage Sludge For

607 Agricultural Use. In: Langenkamp, H., Part, P. (Eds.). European Commission Joint

608 Research Centre Institute for Environment and Sustainability Soil and Waste Unit. 
609 Fabrellas, B., Larrazabal, D., Martinez, M.A., Eljarrat, E., Barcelo, D., 2004. Presence

610 of Polybrominated Diphenyl Ethers in Spanish Sewage Sludges: Important

611 Contribution of Deca-BDE. Organohalogen Compounds 66, 3755-3760.

612 Hagenmaier, H., She, J., Benz, T., Dawidowsky, N., Dusterhoft, L., Lindig, C., 1992.

613 Analysis of sewage sludge for polyhalogenated dibenzo-p-dioxins, dibenzofurans, and 614 diphenylethers. Chemosphere 25, 1457.

615 Hale, R., M. La Guardia, E. Harvey, M. Gaylor, T. Mainor, W. Duff, 2001. Persistent

616 pollutants in land-applied sludges. Nature 412, 140-141.

617 Hale, R.C., La Guardia, M.J., Harvey, E., Matt Mainor, T., 2002. Potential role of fire 618 retardant-treated polyurethane foam as a source of brominated diphenyl ethers to the

619 US environment. Chemosphere 46, 729-735.

620 Hamm, S., 2004. Polybrominated Diphenyl Ethers in Sewage Sludge and Effluents of

621 Sewage Plants from a Central Region of Germany. Organohalogen Compounds 66, $622 \quad 1629-1634$.

623 Harden, F., Muller, J., Toms, L., 2005. Organochlorine Pesticides (OCPs) and 624 Polybrominated Diphenyl Ethers (PBDEs) in the Australian Population: Levels in 625 Human Milk. Environment Protection and Heritage Council of Australia and New 626 Zealand, Canberra.

627 Harrad, S., Porter, L., 2007. Concentrations of polybrominated diphenyl ethers in 628 blood serum from New Zealand. Chemosphere 66, 2019.

629 Hassanin, A., Breivik, K., Meijer, S.N., Steinnes, E., Thomas, G.O., Jones, K.C., 630 2004. PBDEs in European Background Soils: Levels and Factors Controlling Their 631 Distribution. Environ. Sci. Technol. 38, 738-745.

632 Hites, R.A., 2004. Polybrominated diphenyl ethers in the Environment and in People: 633 A meta-analysis of concentrations. Environ. Sci. Technol. 38, 945-956. 
634 IPCS, 1989. Environmental Health Criteria 88: Polychlorinated Dibenzo-p-Dioxins

635 and Dibenzofurans. International Programme on Chemical Safety

636 IPCS, 1994a. Environmental Health Criteria 152: Polybrominated Biphenyls.

637 International Programme on Chemical Safety.

638 IPCS, 1994b. Environmental Health Criteria 162: Brominated Diphenyl Ethers.

639 International Programme on Chemical Safety.

640 IPCS, 1998. Environmental Health Criteria 205: Polybrominated Dibenzo-p-Dioxins

641 and DIbenzofurans.

642 Knoth, W., Mann, W., Meyer, R., Nebhuth, J., 2007. Polybrominated diphenyl ether

643 in sewage sludge in Germany. Chemosphere 67, 1831-1837.

644 Law, R.J., Allchin, C.R., de Boer, J., Covaci, A., Herzke, D., Lepom, P., Morris, S.,

645 Tronczynski, J., de Wit, C.A., 2006. Levels and trends of brominated flame retardants

646 in the European environment. Chemosphere 64, 187-208.

647 Legler, J., Brouwer, A., 2003. Are brominated flame retardants endocrine disruptors?

648 Environ. Int. 29, 879-885.

649 McDonald, T.A., 2002. A perspective on the potential health risks of PBDEs.

650 Chemosphere 46, 745-755.

651 NICNAS, 2001. Polybrominated flame retardants (PBFs): Priority existing chemical

652 assessment report No. 20. National Industrial Chemicals Notification and

653 Assessment Scheme, Sydney, Australia.

654 NICNAS, 2007. NICNAS Information Sheet PBDEs: Interim Public Health Risk

655 Assessment Report on Certain PBDE Congeners Contained In Commercial

656 Preparations of Pentabromodiphenyl Ether and Octabromodiphenyl Ether. In:

657 Australian Government: Department of Health and Ageing (Ed.), Canberra, Australia. 
658 Noren, K., Meironyte, D., 1998. Contaminants in Swedish human milk. Decreasing

659 levels of organochlorine and increasing levels of organobromine compounds.

660 Organohalogen Compounds 38, 1-4.

661 Noren, K., Meironyte, D., 2000. Certain organochlorine and organobromine

662 contaminants in Swedish human milk in perspective of past 20-30 years.

663 Chemosphere 40, 1111-1123.

664 North, K.D., 2004. Tracking Polybrominated Diphenyl Ether Releases in a

665 Wastewater Treatment Plant Effluent, Palo Alto, California. Environ. Sci. Technol.

$66638,4484-4488$.

667 NRMMC, 2004. National Water Quality Management Strategy - Guidelines for

668 Sewerage Systems: Biosolids Management. Department of the Environment and

669 Water Resources, Australian Government, Canberra.

670 Nylund, K., Asplund, L., Jansson, B., Jonsson, P., Litzen, K., Sellstrom, U., 1992.

671 Analysis of some polyhalogenated organic pollutants in sediment and sewage sludge.

672 Chemosphere 24, 1721-1730.

673 Oberg, K., Warman, K., Oberg, T., 2002. Distribution and levels of brominated flame

674 retardants in sewage sludge. Chemosphere 48, 805-809.

675 Pettigrew, A., 1994. Halogenated Flame Retardants. Kirk-Othmer Encyclopedia of

676 Chemical Technology 4th Edition. New York: Wiley, pp. 954-976.

677 Rappe, C., Andersson, R., Bonner, M., Cooper, K., Fiedler, H., Howell, F., 1998.

678 PCDDs and PCDFs in municipal sewage sludge and effluent from potw in the state of

679 Mississippi, USA. Chemosphere 36, 315-328.

680 Schecter, A., Papke, O., Harris, T.R., Tung, K.C., Musumba, A., Olson, J., Birnbaum,

681 L., 2006. Polybrominated Diphenyl Ether (PBDE) Levels in an Expanded Market 
682 Basket Survey of U.S. Food and Estimated PBDE Dietry Intake by Age and Sex.

683 Environ. Health. Persp. 114, 1515-1520.

684 Schmid, P., Kohler, M., Gujer, E., Zennegg, M., Lanfranchi, M., 2007. Persistent

685 organic pollutants, brominated flame retardants and synthetic musks in fish from

686 remote alpine lakes in Switzerland. Chemosphere 67, S16-S21.

687 Schuhmacher, M., Kiviranta, H., Vartiainen, T., Domingo, J.L., 2007. Concentrations

688 of polychlorinated biphenyls (PCBs) and polybrominated diphenyl ethers (PBDEs) in

689 milk of women from Catalonia, Spain. Chemosphere 67, S295-S300.

690 Sellstrom, U., de Wit, C.A., Lundgren, N., Tysklind, M., 2005. Effect of Sewage-

691 Sludge Application on Concentrations of Higher-Brominated Diphenyl Ethers in Soils

692 and Earthworms. Environ. Sci. Technol. 39, 9064-9070.

693 Sellstrom, U., Kierkegaard, A., Alsberg, T., Jonsson, P., Wahlberg, C., Wit, C.d.,

694 1999. Brominated Flame Retardants in Sediments From European Estuaries, the

695 Baltic Sea and in Sewage Sludge. Organohalogen Compounds 40, 383-386.

696 She, J., Holden, A., Sharp, M., Tanner, M., Williams-Derry, C., Hooper, K., 2007.

697 Polybrominated diphenyl ethers (PBDEs) and polychlorinated biphenyls (PCBs) in

698 breast milk from the Pacific Northwest. Chemosphere 67, S307-S317.

699 Sjodin, A., Jakobsson, E., Kierkegaard, A., Marsh, G., Sellstrom, U., 1998. Gas

700 chromatographic identification and quantification of polybrominated diphenyl ethers

701 in a commercial product, Bromkal 70-5DE. Journal of Chromatography A 822, 83-89.

702 Sundstrom, G., Hutzinger, O., Safe, S., 1976. Identification of 2,2',4,4',5,5'-

703 hexabromobiphenyl as the major component of flame retardant fireMaster (R)BP-6.

704 Chemosphere 5, 11-14. 
705 U.S. EPA, 1994. Method 1613: Tetra- through Octa- Chlorinated Dioxins and Furans

706 by Isotope Dilution HDGC/HRMS. U.S. Environmental Protection Agency -

707 Engineering and Analysis Division Washington.

708 U.S. EPA, 1999. Standards for the use or disposal of sewage sludge. 40CFR Part 503.

709 Proposed rule. Federal Register 64 (246): 72045-72062. U.S. EPA.

710 Wang, Y., Zhang, Q., Lv, J., Li, A., Liu, H., Li, G., Jiang, G., 2007. Polybrominated

711 diphenyl ethers and organochlorine pesticides in sewage sludge of wastewater

712 treatment plants in China. Chemosphere 68, 1683-1691.

713

714

715 
715

Table 1

Names and congener numbers of prominent PBDEs and PBBs

\begin{tabular}{lll}
\hline Homologue & $\begin{array}{l}\text { IUPAC } \\
\text { No }\end{array}$ & Bromine Substitution \\
\hline Tetra & 47 & $2,2^{\prime}, 4,4^{\prime}$ \\
Penta & 99 & $2,2^{\prime}, 4,4^{\prime}, 5$ \\
Penta & 100 & $2,2^{\prime}, 4^{\prime}, 6$ \\
Hexa & 153 & $2,2^{\prime}, 4^{\prime}, 4^{\prime}, 5,5^{\prime}$ \\
Hexa & 154 & $2,2^{\prime}, 4,4^{\prime}, 5,6^{\prime}$ \\
Hepta & 183 & $2,2^{\prime}, 3,4,4^{\prime}, 5^{\prime}, 6$ \\
Deca & 209 & $2,2^{\prime}, 3,3^{\prime}, 4,4^{\prime}, 5,5^{\prime}, 6,6^{\prime}$ \\
\hline
\end{tabular}

716

717 
Table 2

Major trade names and manufacturers of technical-grade PBBs and commercial PBB mixtures

\begin{tabular}{llll}
\hline PBB mixture & Trade Name & Manufacturer & CAS No. \\
\hline HexaBBs & FireMaster(R) BP-6 & Michigan Chemical Corp. (St. Louis, Mich.) & $59536-65-1$ \\
& FireMaster(R) FF-1b & Michigan Chemical Corp. (St. Louis, Mich.) & $67774-32-7$ \\
Octa/nonaBBs & Bromkal 80-9D & Chemische Fabrik Kalk (Cologne, Germany) & $61288-13-9$ \\
& Technical octabromobiphenyl & White Chemical Corp. (Bayonne, New Jersey) & \\
& Octabromobiphenyl FR 250 & Dow Chemical Co. (Midland, Mich.) & \\
13A & & Ugine Kuhlmann now Atochem (Paris, France) & $13654-09-6$ \\
Adine 0102 & Berk (London, United Kingdom) & \\
& Flammex B-10 & Berk (London, United Kingdom) & White Chemical Corp. (Bayonne, New Jersey) \\
& Technical decabromobiphenyl & Hexcel (Basildon, United Kingdom) \\
\hline
\end{tabular}

Reproduced from (IPCS, 1994a)

718 
Table 3

Concentration of PBDE -47, -99, -100 and -209 $\mu \mathrm{g} \mathrm{kg}^{-1} \mathrm{~d} . \mathrm{w}$. in sewage sludge from waste water treatment plants reported in the English-language peer reviewed scientific literature.

\begin{tabular}{|c|c|c|c|c|c|}
\hline Country & Reference & BDE-47 & BDE-99 & BDE-100 & BDE-209 \\
\hline Sweden & Nylund, 1992 & 15,15 & 19,19 & & \\
\hline Sweden & $\begin{array}{l}\text { Sellstrom, } \\
1999\end{array}$ & $78,80,36$ & $98,100,56$ & $24,25,13$ & $220,270,170$ \\
\hline U.S.A. & Hale, 2001 & $\begin{array}{l}498,754,359 \\
525,518,673, \\
536,605,421 \\
686,674\end{array}$ & $\begin{array}{l}743,1157, \\
513,584,714, \\
815,516,572, \\
391,648,613\end{array}$ & $\begin{array}{l}106,67,88.5 \\
200,115,255 \\
112,125,113, \\
129,176\end{array}$ & $\begin{array}{l}308,1460, \\
553,84.8, \\
1940,4890, \\
368\end{array}$ \\
\hline Spain & Fabrellas, 2004 & $\begin{array}{l}83.6,21.4, \\
28.3,1.8 \\
49.8,38.5\end{array}$ & $\begin{array}{l}64.2,23.4, \\
25.6,37.6, \\
34.5\end{array}$ & $\begin{array}{l}14.0,4.5,5.7 \\
0.2,8.0,7.7\end{array}$ & $\begin{array}{l}5430,756, \\
1203,3591, \\
5837,18632\end{array}$ \\
\hline Germany & Hamm, 2004 & $\begin{array}{l}25.2,51.7 \\
35.2,55.0 \\
26.7,35.4, \\
88.0,62.7\end{array}$ & $\begin{array}{l}37,72.2,59.3 \\
76.9,39.0 \\
54.2,126.6 \\
94.2\end{array}$ & $\begin{array}{l}5.9,11.0,7.0 \\
12.1,6.1,8.5 \\
19.0,14.4\end{array}$ & $\begin{array}{l}217,198,639, \\
400,177,100, \\
268,609\end{array}$ \\
\hline U.S.A. & North, 2004 & 757 (mean) & 944 (mean) & 165 (mean) & 1183 (mean) \\
\hline China & Wang, 2007 & $\begin{array}{l}5.0(\text { mean }) \\
0.4 \rightarrow 58.7\end{array}$ & $\begin{array}{l}4.5(\text { mean }), \\
<3.4 \rightarrow 69.7\end{array}$ & $\begin{array}{l}1.0(\text { mean }), \\
<24.4 \rightarrow 18.4\end{array}$ & $\begin{array}{l}68.5(\text { mean }) \\
<1 \rightarrow 1108.7\end{array}$ \\
\hline
\end{tabular}


Table 4

Australian Sewage Sludge Survey 2006 - Type of treatment process and source of wastewater; $\mathbf{U}$ $=$ Urban, $\mathbf{R}=$ Rural

\begin{tabular}{|c|c|c|c|}
\hline WWTP & Population $^{1}$ & Treatment Method & Source \\
\hline U1 & $4,297,000$ & $\begin{array}{l}\text { Anaerobically digested and freshly } \\
\text { dewatered. }\end{array}$ & $\begin{array}{l}\text { Services residential and } \\
\text { industrial areas. }\end{array}$ \\
\hline $\mathrm{U} 2$ & $1,811,000$ & Activated Sludge, Dewatered. & $\begin{array}{l}\text { Composition industrial and } \\
\text { domestic. }\end{array}$ \\
\hline $\mathrm{U} 3$ & $1,139,000$ & $\begin{array}{l}\text { Activated sludge. Dissolved air-flotation } \\
\text { filtration. }\end{array}$ & $\begin{array}{l}\text { Mixture of domestic and } \\
\text { industrial and some groundwater } \\
\text { runoff. }\end{array}$ \\
\hline $\mathrm{U} 4$ & $1,139,000$ & Integrated fixed-film activated sludge. & $\begin{array}{l}\text { Mixture of domestic and } \\
\text { industrial and some groundwater } \\
\text { runoff. }\end{array}$ \\
\hline U5 & $3,850,000$ & $\begin{array}{l}\text { Activated sludge plant. Anaerobically } \\
\text { digested primary and secondary sludge. } \\
\text { Dewatered in sludge drying pans. } \\
\text { Stockpiled for }>3 \text { years. }\end{array}$ & Industrial and domestic \\
\hline U6 & $1,508,000$ & $\begin{array}{l}\text { Mesophilic anaerobic digestion, } \\
\text { centrifuge dewatering, }\end{array}$ & $\begin{array}{l}\text { Mainly domestic } \sim 2 \% \text { industrial } \\
\text { input. }\end{array}$ \\
\hline U7 & $1,508,000$ & $\begin{array}{l}\text { Activated sludge. Mechanically } \\
\text { dewatered. Chemically stabilized (lime). }\end{array}$ & $\begin{array}{l}\text { Mainly domestic, } \sim 5 \% \\
\text { industrial. }\end{array}$ \\
\hline U8 & $1,508,000$ & $\begin{array}{l}\text { Mesophilic anaerobic digestion, } \\
\text { centrifuge dewatering, }\end{array}$ & $\begin{array}{l}\text { Mainly domestic } \sim 9 \% \text { industrial } \\
\text { input }\end{array}$ \\
\hline $\mathrm{R} 1$ & 142,000 & $\begin{array}{l}\text { Stored in a lagoon for } 6 \text { months. } \\
\text { Dewatered by centrifuge and stockpiled } \\
\text { for } 4 \text { months. }\end{array}$ & $92 \%$ domestic $8 \%$ trade waste. \\
\hline $\mathrm{R} 2$ & 106,000 & Lagoon. Dewatered by vacuum filtration & Domestic and light industrial. \\
\hline $\mathrm{R} 3$ & 27,000 & Activated sludge. Dewatered. & Domestic source. \\
\hline R4 & 35,000 & Aerobic digestion. Dewatered. & Domestic and light industrial. \\
\hline R5 & 202,000 & Chemically stabilized with lime. & Domestic and industrial \\
\hline R6 & 52,000 & $\begin{array}{l}\text { Dewatered and chemically stabilized } \\
\text { (lime). }\end{array}$ & Mainly domestic. \\
\hline R7 & 5,000 & $\begin{array}{l}\text { Activated sludge and lagoon process. } \\
\text { Land dried. }\end{array}$ & Domestic and abattoir \\
\hline $\mathrm{R} 8$ & 14,000 & Oxidation treatment pond. Solar dried. & Domestic and Industrial \\
\hline
\end{tabular}

${ }^{I}$ Population refers to the population of the town/city and not just the feeding population of the WWTP 
Table 5

Perth WWTPs that the sewage sludge concentration of PBDEs was measured in 2005 and 2006

Beenyup

Woodman Point
$110 \mathrm{ML} /$ day, mesophilic anaerobic digestion, centrifuge dewatering, $\sim 2 \%$ industrial input

$60 \mathrm{ML} /$ day dewatered and chemically stabilized. Mainly domestic. $\sim 5 \%$ industrial input

$120 \mathrm{ML} /$ day mesophilic anaerobic digestion, centrifuge dewatering, 9\% industrial input

723 
Table 6

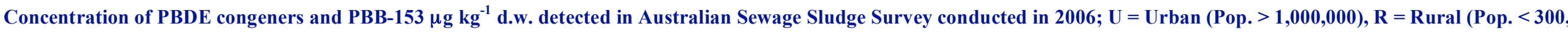

\begin{tabular}{|c|c|c|c|c|c|c|c|c|c|c|c|c|c|c|c|c|}
\hline & $\mathbf{U} 1$ & $\mathbf{U} 2$ & $\mathbf{U 3}$ & $\mathrm{U} 4$ & U5 & $\mathrm{U} 6^{3}$ & U7 & $\mathbf{U 8}^{3}$ & $\begin{array}{l}\text { Urban } \\
\text { Mean }\end{array}$ & Sd & $\mathbf{R} 1$ & $\mathbf{R 2}$ & R3 & $\mathbf{R 4}$ & R5 & R6 \\
\hline BDE 17 & 0.96 & 2.7 & 2.7 & 0.27 & 0.16 & 7.75 & 0.46 & 1.85 & 2.1 & 2.5 & 4.3 & 0.25 & 12 & 2.6 & 0.69 & 0.4 \\
\hline BDE $28+33$ & 2 & 3.1 & 25 & 1.1 & $<0.2$ & 4.55 & 0.85 & 5.2 & 6.0 & 8.6 & 8.1 & 0.92 & 2.6 & 2.4 & 1.2 & 1.4 \\
\hline BDE 30 & $<0.04$ & $<0.02$ & $<0.06$ & $<0.02$ & $<0.03$ & $<\mathrm{dl}$ & $<0.03$ & $<\mathrm{dl}$ & - & - & 0.14 & $<0.006$ & 0.012 & $<0.06$ & $<0.05$ & $<0.03$ \\
\hline BDE 47 & 120 & 180 & 36 & 72 & 17 & 205 & 45 & 285 & 120.0 & 95.4 & 170 & 74 & 120 & 140 & 56 & 89 \\
\hline BDE 49 & 3.8 & 5.6 & 2.3 & 2.3 & 1.9 & 7.95 & 1.5 & 8.45 & 4.2 & 2.8 & 16 & 1.9 & 6.4 & 5.6 & 2 & 3.1 \\
\hline BDE 66 & 3.3 & 6.1 & 1.4 & 2.9 & 0.59 & 7.15 & 1.5 & 7.7 & 3.8 & 2.8 & 8.4 & 1.9 & 4.2 & 4.8 & 1.7 & 2.8 \\
\hline BDE 71 & $<0.2$ & $<2$ & $<0.2$ & $<0.3$ & $<0.06$ & $<\mathrm{dl}$ & $<0.2$ & $<\mathrm{dl}$ & - & - & 1.6 & 0.17 & 8 & 1.9 & $<4$ & 0.18 \\
\hline BDE 77 & 0.049 & 0.055 & 0.0099 & $<0.01$ & $<0.004$ & 0.58 & $<0.03$ & 0.092 & 0.2 & 0.2 & 0.1 & 0.027 & 0.06 & 0.069 & $<0.03$ & 0.06 \\
\hline BDE 85 & 4.8 & 6.7 & 1.1 & 3.1 & 1 & 8.8 & 1.8 & 11.5 & 4.9 & 3.9 & 5.1 & 5.8 & 3.9 & 5.8 & 1.8 & 4.2 \\
\hline BDE 99 & 130 & 190 & 31 & 84 & 22 & 230 & 48 & 315 & 131.0 & 106.0 & 210 & 120 & 130 & 170 & 51 & 130 \\
\hline BDE 100 & 26 & 39 & 8.6 & 16 & 4.4 & 47.5 & 9.6 & 63.5 & 27.0 & 21.0 & 41 & 21 & 24 & 32 & 11 & 21 \\
\hline BDE 119 & $<0.9$ & $<1$ & $<0.1$ & $<0.4$ & 0.04 & 0.695 & 0.11 & 0.465 & 0.33 & 0.31 & 0.28 & 0.14 & 0.28 & 0.29 & $<0.6$ & 0.21 \\
\hline BDE 126 & $<3$ & $<0.04$ & $<0.5$ & $<0.02$ & $<0.5$ & 0.805 & $<0.02$ & $<\mathrm{dl}$ & - & - & $<0.1$ & $<0.02$ & $<0.02$ & $<0.02$ & $<0.03$ & $<0.02$ \\
\hline BDE 138 + 166 & & & & & & 3.3 & 1.9 & 2.7 & 2.6 & 0.7 & 4.2 & 4.7 & 3.9 & 6.1 & nd & 4.2 \\
\hline BDE 139 & 1.5 & 2 & 0.49 & 0.82 & 0.31 & 2.8 & 0.42 & 3.15 & 1.4 & 1.1 & 1.6 & 1.9 & 1.1 & 1.5 & 0.4 & 1.3 \\
\hline BDE 140 & 0.45 & 0.71 & 0.18 & 0.29 & 0.16 & 1.27 & 0.13 & 0.84 & 0.50 & 0.41 & 0.61 & 0.54 & 0.47 & 0.59 & 0.16 & 0.36 \\
\hline BDE 153 & 13 & 20 & 4.8 & 8.2 & 4.9 & 23 & 4.4 & 28 & 13.3 & 9.3 & 23 & 14 & 13 & 17 & 4.6 & 13 \\
\hline
\end{tabular}




\begin{tabular}{|c|c|c|c|c|c|c|c|c|c|c|c|c|c|c|c|c|}
\hline BDE 154 & 10 & 16 & 4.3 & 6.1 & 3.2 & 19.5 & 3.9 & 24.5 & 10.9 & 8.1 & 19 & 9.8 & 12 & 15 & 3.8 & 8.4 \\
\hline BDE $156+169$ & & & & & & 4.8 & $<0.1$ & $<\mathrm{dl}$ & - & - & $<0.09$ & $<0.08$ & $<0.06$ & $<0.1$ & nd & $<0.1$ \\
\hline BDE 171 & $<0.09$ & $<0.2$ & 0.097 & $<0.4$ & 0.41 & 3.87 & 0.099 & 0.375 & 0.97 & 1.63 & 0.38 & 0.11 & 0.17 & 0.27 & 0.13 & 0.2 \\
\hline BDE 180 & 0.37 & 1.7 & 0.14 & 0.29 & 0.81 & 3.945 & 0.11 & 0.615 & 1.00 & 1.30 & 0.57 & 0.17 & 0.26 & 0.41 & 0.16 & 0.33 \\
\hline BDE 183 & 9.6 & 19 & 3.9 & 5.1 & 15 & 13 & 1.9 & 10 & 9.7 & 5.9 & 13 & 3.3 & 3.7 & 11 & 3.3 & 7.3 \\
\hline BDE 184 & 0.16 & 0.39 & 0.094 & 0.11 & 0.2 & 2.23 & 0.064 & 0.41 & 0.46 & 0.73 & 0.67 & 0.098 & 0.2 & 0.47 & 0.075 & 0.19 \\
\hline BDE 191 & 0.098 & 0.33 & 0.061 & 0.053 & 1.1 & 2.805 & $<0.04$ & $<\mathrm{dl}$ & - & - & 0.2 & 0.047 & 0.14 & 0.092 & 0.053 & 0.082 \\
\hline BDE 196 & 4.7 & 7.7 & $<0.2$ & $<1$ & $<2$ & 7.4 & 1.6 & 4.2 & 5.1 & 2.5 & 6.4 & 2.2 & 4.7 & 4.2 & 3 & 4.3 \\
\hline BDE 197 & 2.9 & 3.6 & 0.89 & 1.1 & 8.4 & 8.75 & 0.85 & 4.3 & 3.8 & 3.2 & 6.6 & 1.4 & 2.2 & 5.4 & 1.5 & 3 \\
\hline BDE 201 & 1.1 & $<4$ & $<1$ & $<0.7$ & 14 & 4.85 & 0.38 & 1.3 & 4.3 & 5.7 & 2.8 & 0.44 & 1.8 & 1.2 & 0.59 & 1 \\
\hline BDE 203 & $<3$ & $<3$ & $<1$ & $<2$ & 40 & 8.35 & 1.3 & 5.1 & 13.7 & 17.8 & 7.8 & 2.4 & 5.7 & 4.5 & 2.3 & 3.7 \\
\hline BDE 204 & 1.4 & $<3$ & 0.64 & 0.97 & $<7$ & 8.2 & $<0.1$ & $<\mathrm{dl}$ & - & - & $<0.4$ & $<0.06$ & $<0.1$ & $<0.4$ & $<0.1$ & $<0.2$ \\
\hline BDE 205 & $<1$ & $<0.7$ & $<0.4$ & $<0.6$ & $<2$ & 7.8 & $<0.2$ & $<\mathrm{dl}$ & - & - & $<0.3$ & $<0.2$ & $<0.09$ & $<0.2$ & $<0.3$ & $<0.2$ \\
\hline BDE 206 & 32 & 9.7 & 3.1 & 4.5 & 98 & 30 & 6 & 27.5 & 26 & 31 & 28 & 7.6 & 31 & 8.5 & 8.2 & 7.9 \\
\hline BDE 207 & 13 & 12 & 5.7 & 6 & 110 & 19.5 & 6.3 & 12.5 & 23 & 35 & 21 & 5.9 & 20 & 8.7 & 7.4 & 9.9 \\
\hline BDE 208 & 7.9 & 6.5 & 2.7 & 2.8 & 97 & 15.7 & 3.7 & 7.95 & 18 & 32 & 14 & 3.4 & 10 & 4.4 & 3.9 & 5.7 \\
\hline BDE 209 & 1170 & 360 & 93 & 81 & 3780 & 530 & 130 & 910 & 882 & 1237 & 990 & 280 & 1210 & 260 & 250 & 180 \\
\hline$\Sigma \mathrm{PBDE}^{1}$ & 1560 & 900 & 230 & 300 & 4230 & 1225 & 280 & 1735 & 1308 & 1320 & 1610 & 560 & 1630 & 710 & 420 & 500 \\
\hline PBB-153 & 0.52 & 2.2 & 0.38 & 0.58 & 1 & 0.59 & 0.22 & 0.63 & 0.8 & 0.6 & 0.65 & 0.33 & 0.037 & 0.2 & 0.45 & 0.69 \\
\hline
\end{tabular}

${ }^{I}$ Does not include half detection limit

${ }^{2}$ The Standard Error associated with replicate sampling and analytical measurement calculated from five replicate samples as part of the time series study

${ }^{3}$ Reported is the average concentration of replicate samples 
Table 7

The first three principal components of PBDEs in Australian sewage sludge conducted in 2006

\begin{tabular}{|c|c|c|c|}
\hline & PCA1 & PCA2 & PCA3 \\
\hline BDE 17 & 0.5030 & 0.0164 & 0.2822 \\
\hline BDE 47 & 0.8898 & 0.2918 & -0.3169 \\
\hline BDE 49 & 0.8089 & 0.1733 & -0.3736 \\
\hline BDE 66 & 0.8988 & 0.2629 & -0.2819 \\
\hline BDE 77 & 0.7261 & -0.0975 & 0.6562 \\
\hline BDE 85 & 0.8870 & 0.2923 & -0.2483 \\
\hline BDE 99 & 0.9034 & 0.2976 & -0.2914 \\
\hline BDE 100 & 0.8972 & 0.2858 & -0.3137 \\
\hline BDE 119 & 0.8906 & 0.0920 & 0.0651 \\
\hline BDE 139 & 0.9042 & 0.2732 & -0.1840 \\
\hline BDE 140 & 0.9676 & 0.1523 & 0.0951 \\
\hline BDE 153 & 0.9239 & 0.2427 & -0.2628 \\
\hline BDE 154 & 0.9222 & 0.2536 & -0.2825 \\
\hline BDE 171 & 0.6347 & -0.2354 & 0.7016 \\
\hline BDE 180 & 0.6907 & -0.2486 & 0.6147 \\
\hline BDE 183 & 0.6602 & -0.3824 & -0.1411 \\
\hline BDE 184 & 0.7384 & -0.1603 & 0.6340 \\
\hline BDE 191 & 0.5491 & -0.5078 & 0.6454 \\
\hline BDE 196 & 0.6814 & 0.1676 & 0.1891 \\
\hline BDE 197 & 0.7047 & -0.6217 & 0.0754 \\
\hline BDE 201 & 0.2322 & -0.9579 & -0.1157 \\
\hline BDE 203 & 0.1765 & -0.9340 & -0.242 \\
\hline BDE 206 & 0.2963 & -0.8839 & -0.2892 \\
\hline BDE 207 & 0.1060 & -0.9571 & -0.2566 \\
\hline BDE 208 & 0.0864 & -0.9627 & -0.2376 \\
\hline BDE 209 & 0.1881 & -0.8721 & -0.3929 \\
\hline
\end{tabular}


Table 8

Concentration of PBDEs $\mu \mathrm{g} \mathrm{kg}^{-1}$ d.w. at sewage sludge measured at three Perth WWTPs (Beenyup, Subiaco and Woodman Point) in the years 2005 and 2006.

\begin{tabular}{|c|c|c|c|c|c|c|c|c|c|c|c|}
\hline \multirow[b]{3}{*}{ BDE 17} & \multicolumn{4}{|c|}{ Beenyup } & \multicolumn{3}{|c|}{ Subiaco } & \multicolumn{4}{|c|}{ Woodman Point } \\
\hline & \multicolumn{2}{|c|}{2005} & \multicolumn{2}{|c|}{2006} & \multicolumn{2}{|c|}{2005} & \multirow{2}{*}{$\begin{array}{r}\mathbf{2 0 0 6} \\
0.46\end{array}$} & \multicolumn{2}{|c|}{2005} & \multicolumn{2}{|c|}{2006} \\
\hline & 3.5 & 3.9 & 7.7 & 7.8 & 1.1 & 1.1 & & 1.6 & 1.5 & 1.8 & 1.9 \\
\hline BDE $28+33$ & 4.6 & 4.6 & 4.6 & 4.5 & 2 & 1.7 & 0.85 & 4.3 & 4.7 & 5.1 & 5.3 \\
\hline BDE 47 & 230 & 210 & 200 & 210 & 71 & 64 & 45 & 230 & 240 & 290 & 280 \\
\hline BDE 49 & 8.4 & 8 & 7.7 & 8.2 & 2.4 & 2.5 & 1.5 & 6.9 & 8 & 8.9 & 8 \\
\hline BDE 66 & 9 & 6.9 & 7.4 & 6.9 & 2.3 & 2.4 & 1.5 & 6.8 & 8.4 & 8.4 & 7 \\
\hline BDE 77 & 0.13 & 0.1 & 1 & 0.16 & 0.024 & 0.025 & $<0.03$ & 0.089 & 0.071 & $<0.1$ & 0.092 \\
\hline BDE 85 & 12 & 13 & 9 & 8.6 & 3.6 & 3.6 & 1.8 & 11 & 13 & 12 & 11 \\
\hline BDE 99 & 250 & 300 & 220 & 240 & 110 & 79 & 48 & 260 & 270 & 330 & 300 \\
\hline BDE 100 & 50 & 62 & 47 & 48 & 23 & 16 & 9.6 & 54 & 56 & 64 & 63 \\
\hline BDE 119 & 0.54 & 0.47 & 0.96 & 0.43 & 0.15 & 0.15 & 0.11 & 0.45 & 0.48 & 0.46 & 0.47 \\
\hline BDE $138+166$ & 3.3 & 2.8 & 4.2 & 2.4 & 0.81 & 0.8 & 1.9 & 3 & 3 & 2.9 & 2.5 \\
\hline BDE 153 & 28 & 29 & 23 & 23 & 8.8 & 8.6 & 4.4 & 27 & 29 & 27 & 29 \\
\hline BDE 154 & 27 & 25 & 18 & 21 & 7.3 & 7.6 & 3.9 & 24 & 24 & 26 & 23 \\
\hline BDE 183 & 16 & 16 & 15 & 11 & 3.5 & 3.4 & 1.9 & 11 & 13 & 10 & 10 \\
\hline BDE 184 & 0.5 & 0.46 & 4 & 0.46 & 0.14 & 0.14 & 0.064 & 0.41 & 0.41 & 0.47 & 0.35 \\
\hline
\end{tabular}




\begin{tabular}{|l|cccc|ccc|ccc|c|} 
BDE 196 & 5.3 & 4.6 & 11 & 3.8 & 1.2 & 1.2 & 1.6 & 3.5 & 3.5 & 4.5 & 3.9 \\
BDE 197 & 9.5 & 9.3 & 12 & 5.5 & 1.9 & 1.9 & 0.85 & 6.2 & 6.1 & 4.6 & 4 \\
BDE 206 & 36 & 34 & 40 & 20 & 6.6 & 7 & 6 & 20 & 25 & 29 & 26 \\
BDE 207 & 50 & 42 & 28 & 11 & 7.8 & 6.6 & 6.3 & 23 & 16 & 14 & 11 \\
BDE 209 & 810 & 830 & 500 & 560 & 260 & 160 & 130 & 480 & 760 & 950 & 870 \\
$\Sigma$ PBDE & 1560 & 1600 & 1250 & 1200 & 510 & 370 & 280 & 1170 & 1480 & 1800 & 1670 \\
\hline
\end{tabular}


(a)

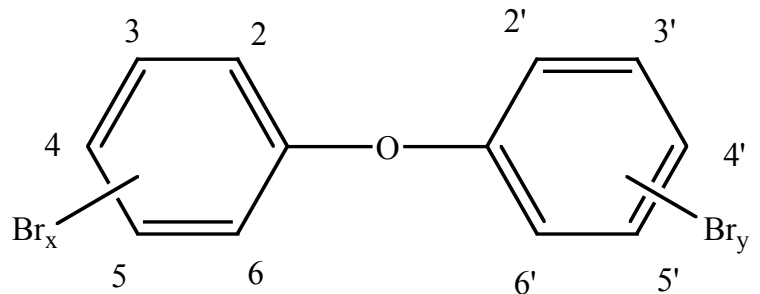

(b)

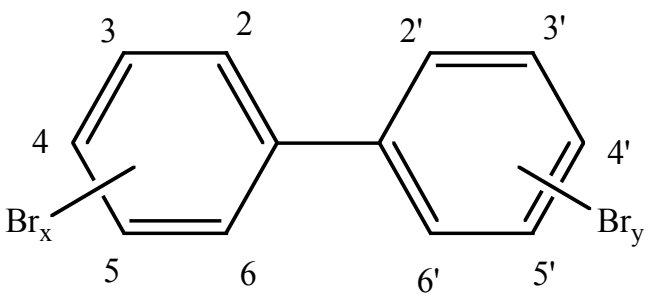

Fig 1. Chemical structure of four common brominated flame retardants (a) polybrominated diphenyl ether and (b) polybrominated biphenyls. 
$\square$ BDE-47 $\square$ BDE-99 $\square$ BDE-209 Total PBDE

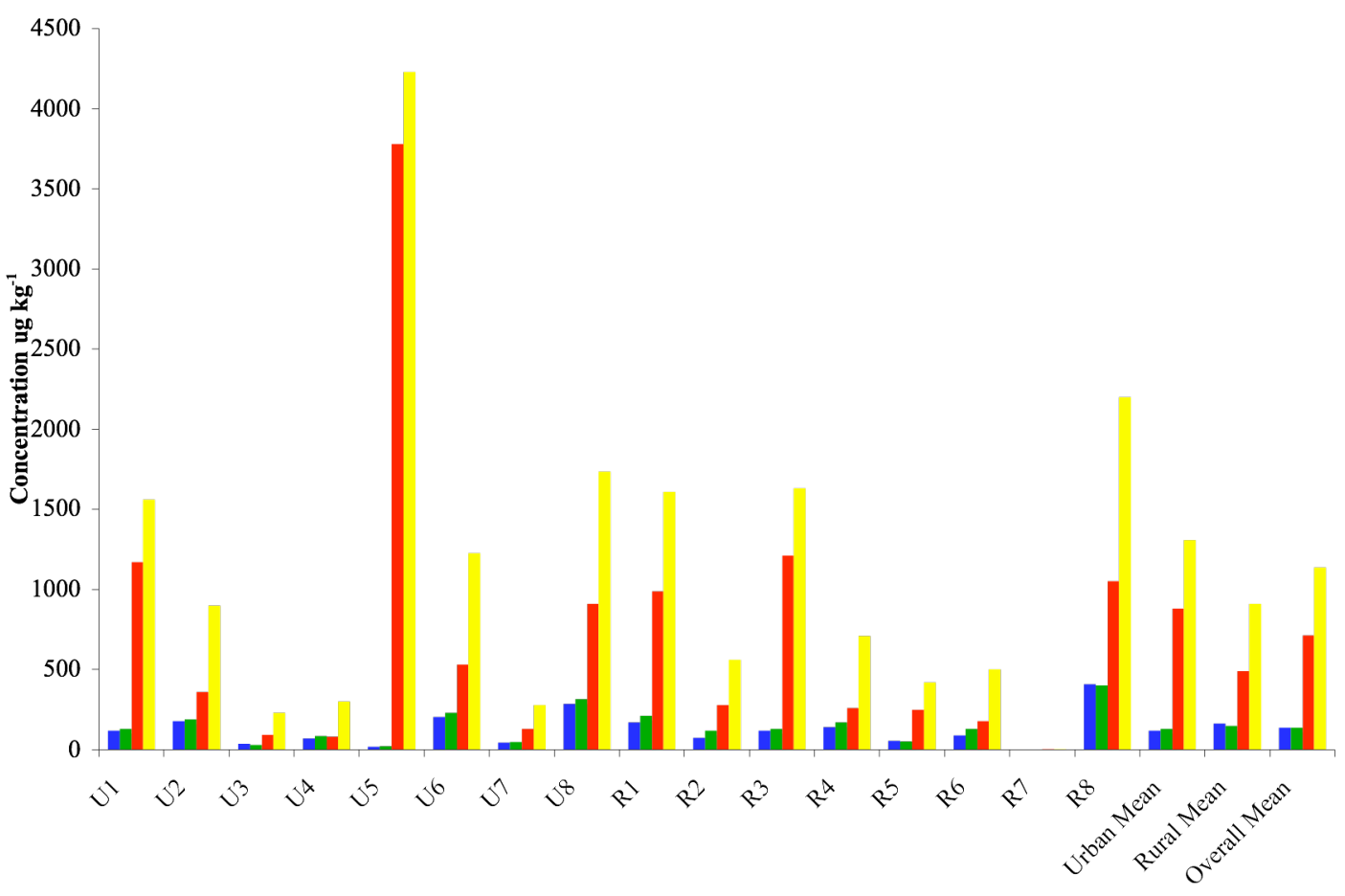

Fig. 2. Concentration of BDE-47, BDE-209 and $\Sigma$ PBDE $\left.\mu \mathrm{g} \mathrm{kg}^{-1}\right)$ in Australian sewage sludge; $\mathrm{U}=$ Urban (Pop. > 1,000,000), $R=$ Rural (Pop. <300,000)

730

731 
(A)

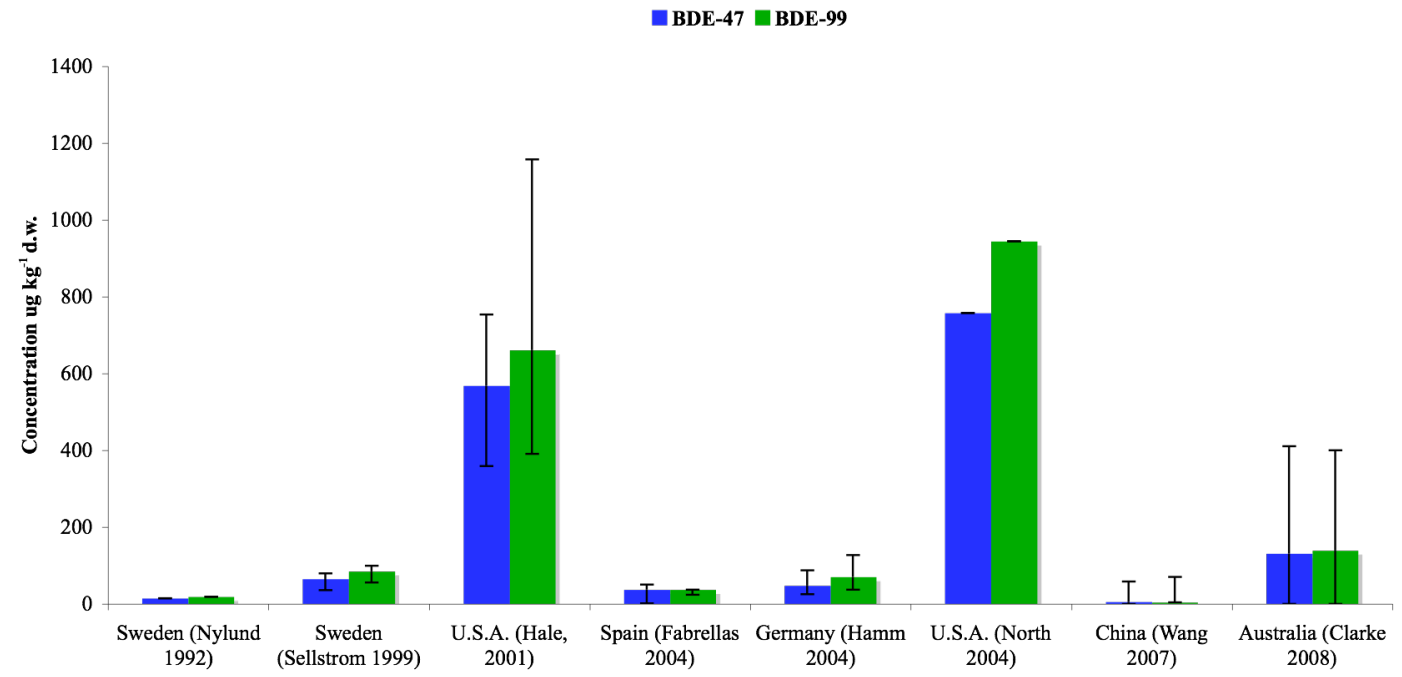

(B)

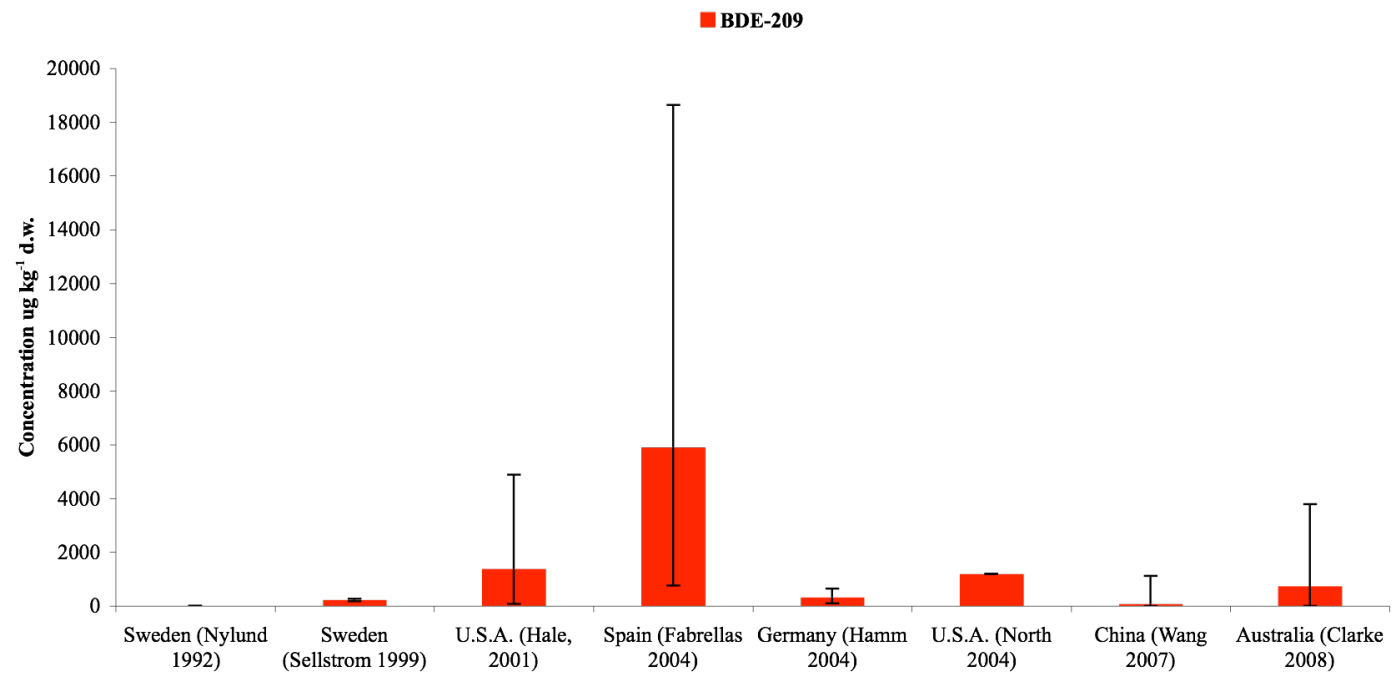

Fig. 3. A comparison of the major PBDE congeners $\mu \mathrm{g} \mathrm{kg}^{-1}$ d.w. (a) BDE-47, -99 and (B) BDE-209 from the Australian survey and the English peer reviewed scientific literature. The graphs represent the mean concentration and the error bars express the range reported. 


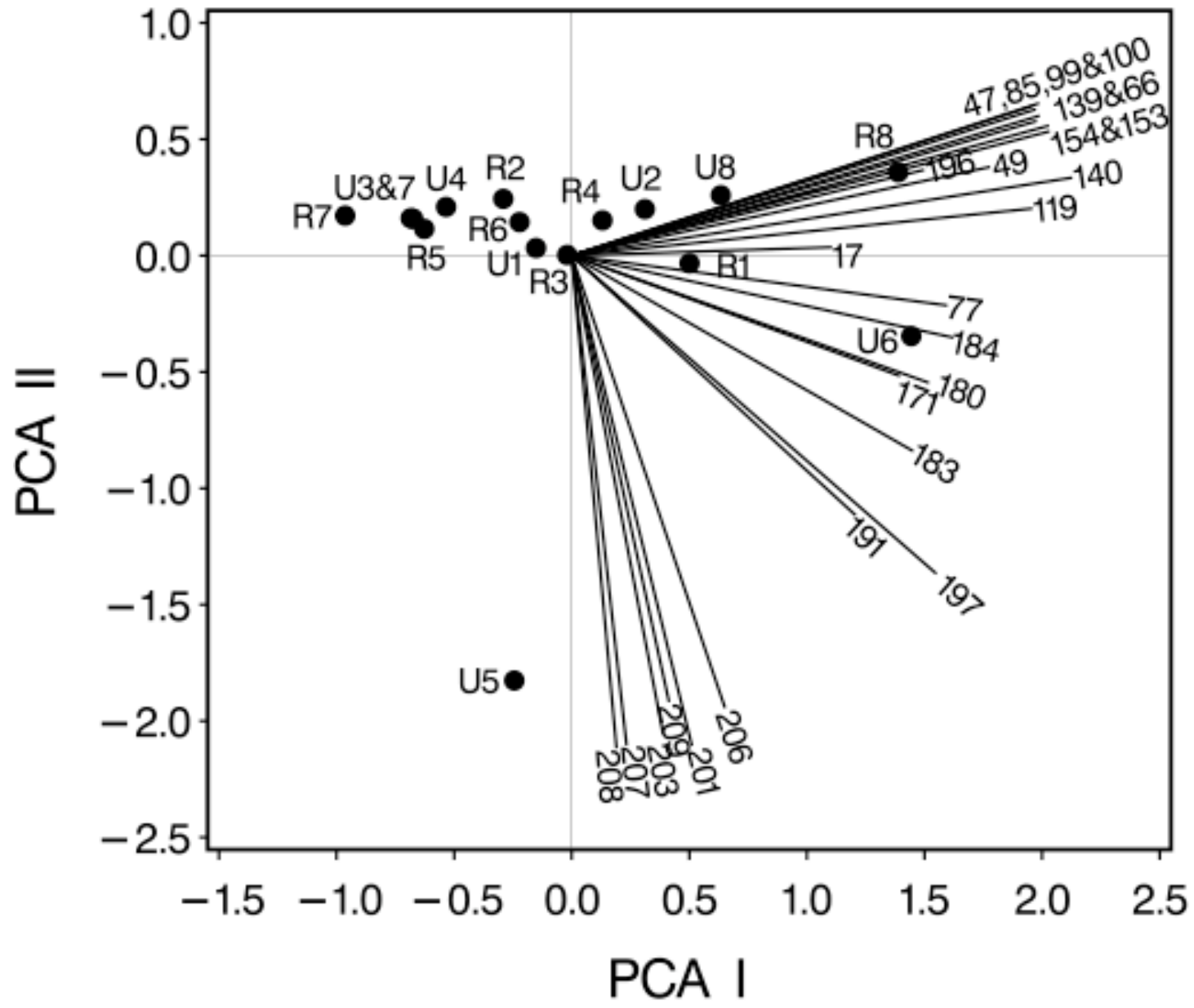

Fig. 4. Principal component analysis of PBDEs in Australian sewage sludge survey conducted in 2006. Plot of PCA1 vs PCA2, primarily representing pentaBDE and decaBDE commercial formulations (A) Score plot (B) Loading Plot. 